\title{
DISTANCE EDUCATION IN THE U.S.: A PARADOX
}

\author{
Dr. Glenn J. FORTE \\ The College of Social \& Behavioral Science, \\ Wilmington University, New Castle, DE, USA
}

Dr. David R. SCHWANDT

The Graduate School of Education \& Human Development The George Washington University, Ashburn, VA, USA

Dr. Susan SWAYZE

Graduate School of Education \& Human Development The George Washington University, Washington, DC, USA

\author{
Dr. Joan BUTLER \\ Clinical Research Department \\ The George Washington University, Washington, DC, USA \\ Dr. Merrill ASHCRAFT \\ Strategic Statistics Consulting \\ Chesapeake, VA, USA
}

\section{ABSTRACT}

Over the last several years distance education (DE) class offerings at U.S. universities and colleges have been increasing at a rate of approximately $10 \%$ or more per year. While the effectiveness of DE classes vis-à-vis that of face-to-face (F2F) classes has been sufficiently documented, there are few studies that compare student evaluations of the two class delivery systems. Therefore, we sought to answer the question, is there a significant difference between student evaluations of the Teaching Methods and Styles (TM\&S) of DE and F2F classes as measured on a student completed class and instructor survey, examined through the lens of Moore's Transactional Distance Theory (TDT) constructs of student autonomy, dialogue and structure. Moore maintains that Transactional Distance (TD) is a psychological and pedagogical separation of student and instructor, as well as a geographical one. The twenty TM\&S questions included in the survey data for 765 classes offered from September 6, 2011 to December 19, 2013 were collected and analyzed for classes identified as SOC 101 Introduction to Sociology through SOC 340 Applied Research in the Behavioral Sciences that are offered by the College of Social and Behavioral Sciences at a Mid-Atlantic Open University. A t-test analysis of variance was conducted and analyzed. The results of the study indicate that 16 of the 20 TM\&S questions returned statistically significant results, 3 of 4 for student autonomy, 8 of 10 for dialogue and 5 of 6 for structure. Three of the TDT construct dialogue/interaction questions and two of the TDT construct structure questions returned medium effect size magnitudes. Three of the TM\&S questions associated with the TDT construct autonomy returned statistically significant results with low effect size magnitudes. Based on the results of the study, we have concluded that psychological and pedagogical separation, or TD between student and instructor is reduced when the DE course structure encourages and requires increased dialogue and interaction.

Keywords: Distance education, distance education paradox, transactional distance and transactional distance theory 


\section{INTRODUCTION}

In a study conducted by Babson Research for the Sloan Consortium, Allen and Seaman (2013) reported that over the last 10 years of research Chief Academic Officers (CAOs) report a less than overwhelming claim for the validity and legitimacy on DE by their respective faculty. As Table 1 below indicates, only about 30\% of those CAOs indicated their faculty's agreement that DE is valid and legitimate. The rest disagree or are neutral on the question suggesting that a large percentage of faculty have yet to make up their minds with respect to the validity and legitimacy of DE. It may be that many of that group have not been exposed to DE classes and are reluctant to make a judgment. Such numbers have led one to assume that faculty members are having difficulty adapting to and accepting DE. If, as is discussed below, students are already uncomfortable with DE and are quick to drop a DE class when they discover the reality of DE classes and faculty members are uncomfortable with DE classes, a problem for the successful growth of DE exists. Yet, in spite of these issues, the number of students enrolled in DE classes increased in 2011 and 2012, albeit at a slower rate than previous years. The Sloan Consortium study estimates that the 2012's growth rate for DE enrollments of "9.3 percent is the lowest recorded in this report series" (Allen \& Seaman, 2013, p. 4).

Table: 1

Faculty Assessment of Legitimacy of Online Education: (Allen \& Seaman, 2013, p. 29)

\begin{tabular}{ccccccccc}
\hline & Fall 2002 & Fall 2004 & Fall 2005 & Fall 2006 & Fall 2007 & Fall 2009 & Fall 2011 & Fall 2012 \\
\hline Agree & $27.6 \%$ & $30.4 \%$ & $27.6 \%$ & $32.9 \%$ & $33.5 \%$ & $30.9 \%$ & $32.0 \%$ & $30.2 \%$ \\
Neutral & $59.3 \%$ & $57.8 \%$ & $56.1 \%$ & $51.9 \%$ & $51.9 \%$ & $51.8 \%$ & $56.5 \%$ & $57.2 \%$ \\
Disagree & $7.4 \%$ & $10.3 \%$ & $14.7 \%$ & $11.0 \%$ & $14.6 \%$ & $17.3 \%$ & $11.4 \%$ & $12.6 \%$ \\
\hline
\end{tabular}

Student dissatisfaction with DE classes, as evidenced by the widening attrition gap between DE classes and traditional F2F classes is becoming an even bigger problem as DE class offerings increase (Patrick, 2009). Moreover, in the most recent Babson Survey Research Study (Allen \& Seaman, 2014), over $\mathbf{4 0 \%}$ of CAOs report that it is more difficult to retain DE students for 2013 and that percentage has increased significantly since 2004 (see Figure 1). 


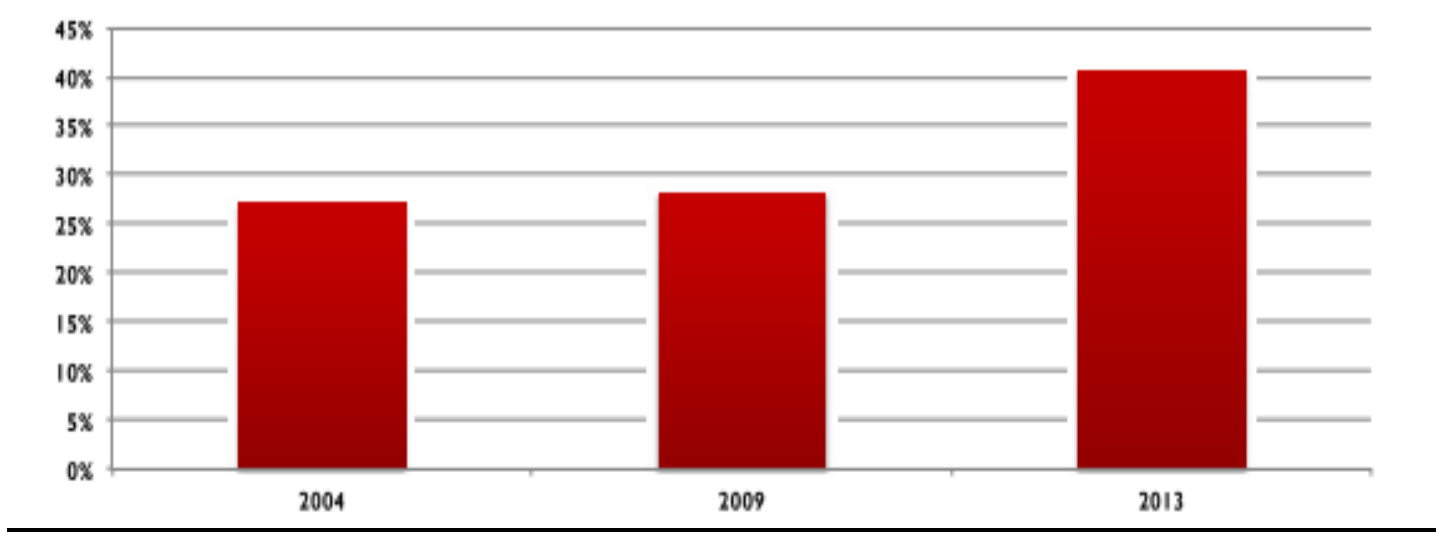

Figure: 1

Retaining Students is a Greater Problem for Online Courses than it is for Face-To-Face Courses (Allen \& Seaman, 2014, p. 18).

Given the incredible development of DE classes throughout the U.S. and the very weak retention numbers cited by Chief Academic Officers, a paradox exists. While there are a number of studies that compare DE classes to F2F classes with similar disappointing results (see Bernard et al., 2004), the current study examined the difference based on students' survey ratings of the teaching methods and styles (TM\&S) for both DE and F2F classes.

\section{MOORE'S TRANSACTIONAL DISTANCE THEORY}

In the early 1970's, Michael G. Moore $(1997,2010)$ focused on a revised explanation of DE. His revision holds that DE is not only a geographical separation but a psychological and pedagogical separation as well. The theory is known as Transactional Distance Theory (TDT). It is based on Dewey's concept of transactional education (See Dewey \& Bently, 1949). They viewed knowledge and its acquisition as occurring in a natural system in which each member of that system is dependent on other members. Therefore, no one stands alone in his or her acquisition of knowledge.

TDT maintains that the greater the transactional (psychological) distance, the less effective the online class. Consequently, Moore's purpose has been to reduce the psychological or transactional distance of DE courses. Moore considered three constructs necessary for TDT. They are student autonomy, dialogue/interaction and course structure. He has hypothesized that "as dialogue increases, transactional distance decreases [and] as structure increases, transactional distance increases" (Moore, 2010, p. 19). Moreover, the need for student autonomy "increases as transactional distance increases" (p. 21). In the end, dialogue appears to be the key variable, as the degree of transactional distance is ultimately dependent upon the level of dialogue, which causes some to consider TDT a tautology and not a viable theory (Gorsky \& Caspi, 2005b). 
Like others (Connolly et al., 2007; Dron et al., 2004; Fulford \& Zhang, 1993; Holmberg, 2003; Lear, Isernhagen, LaCost, \& King, 2009; Salmon \& Shephard, 2004; Tsui \& Ki, 1996), Gorsky et al. (2004), we have concluded that dialogue is important to student satisfaction (see also Gorsky \& Caspi, 2005a). Moreover, they also discovered, as did others (Connolly et al., 2007; Salmon \& Shephard, 2004) the importance of the tutor in motivating students to participate in dialogue. Finally, they came to the realization, as did Dron et al. (2004) that in spite of the importance that theorists like Moore (1993) attached to dialogue, the reality is that very often dialogue has been neglected in DE classes.

\section{THE CONCEPTUAL FRAMEWORK}

The study considered the TM\&S as reported on the student survey through the lens of Moore's Transactional Distance Theory (TDT) (1973, 1997, 2010, 2012). There are 20 IDEA TM\&S variables. Each variable was categorized under one of the constructs of Moore's TDT (Autonomy, Dialogue \& Structure).

The study categorized the 20 TM\&S variables from each IDEA survey and Moore's constructs in the following way.

AUTONOMY: Moore (2012) defined autonomous students as those capable of taking charge of their learning. Table 2 categorizes Moore's TDT construct with 4 survey TM\&S variables.

Table: 2

IDEA TM\&S Categorized with Moore's TDT Construct Autonomy

\begin{tabular}{|c|c|}
\hline $\begin{array}{l}\text { Moore's TDT } \\
\text { Constructs }\end{array}$ & Survey Teaching Methods \& Styles \\
\hline \multirow{4}{*}{ AUTONOMY } & $\begin{array}{l}\text { Stimulated students to intellectual effort beyond that required by most other } \\
\text { courses (IDEA Survey item \#8) }\end{array}$ \\
\hline & Encouraged students to use multiple resources (IDEA Survey item \#9) \\
\hline & $\begin{array}{l}\text { Inspired students to set and achieve goals which really challenged them (IDEA } \\
\text { Survey item \#15) }\end{array}$ \\
\hline & $\begin{array}{l}\text { Gave projects, tests or assignments that require original or creative thought } \\
\text { (IDEA Survey item \#19) }\end{array}$ \\
\hline
\end{tabular}

DIALOGUE: Moore described dialogue as a certain kind of interaction between students and instructors that relies on words and images. Table 3 Categorizes Moore's TDT construct of Dialogue with 10 survey TM\&S variables. 
Table: 3

Survey TM\&S Categorized with Moore's TDT Construct Dialogue

Moore's TDT Constructs

DIALOGUE
Survey Teaching Methods \& Styles

Displayed a personal interest in students and their learning (IDEA Survey \#1)

Found ways to help students answer their own questions (IDEA Survey \#2)

Demonstrated the importance and significance of the subject matter (IDEA Survey \#4)

Formed teams or discussion groups to facilitate learning (IDEA Survey \#5)

Explained the reasons for criticisms of students' academic performance (IDEA Survey \#7)

Introduced stimulating ideas about the subject matter (IDEA Survey \#13)

Asked students to share ideas and experiences with others whose backgrounds and viewpoints differ from their own (IDEA Survey \#16)

Provided timely and frequent feedback on tests, reports, projects, etc. to help students improve (IDEA Survey \#17)

Asked students to help each other understand ideas or concepts (IDEA Survey \#18)

Encouraged student - faculty interaction outside of class (IDEA Survey \#20)

Finally, STRUCTURE: Moore (2012, p. 5) has defined structure as "that which expresses the rigidity or flexibility of the course's educational objectives, teaching strategies, and evaluation methods. Table 4 Categorizes Moore's TDT construct Structure with 6 IDEA TM\&S variables.

Table: 4

Survey TM\&S Categorized with Moore's TDT Construct Structure

\begin{tabular}{|c|c|}
\hline $\begin{array}{l}\text { Moore's TDT } \\
\text { Constructs }\end{array}$ & Survey Teaching Methods \& Styles \\
\hline \multirow{6}{*}{ STRUCTURE } & $\begin{array}{l}\text { Scheduled course work (class activities, tests, projects) in ways which } \\
\text { encouraged students to stay up-to-date in their work (IDEA Survey \#3) }\end{array}$ \\
\hline & Made it clear how each topic fit into the course (IDEA Survey \#6) \\
\hline & Explained course material clearly and concisely (IDEA Survey \#10) \\
\hline & Related course material to real life situations (IDEA Survey \#11) \\
\hline & $\begin{array}{l}\text { Gave tests, projects, etc. that covered the most important points of the course } \\
\text { (IDEA Survey \#12) }\end{array}$ \\
\hline & $\begin{array}{l}\text { Involved students in "hands on" projects such as research, } \\
\text { case studies, or "real life" activities (IDEA Survey \#14) }\end{array}$ \\
\hline
\end{tabular}




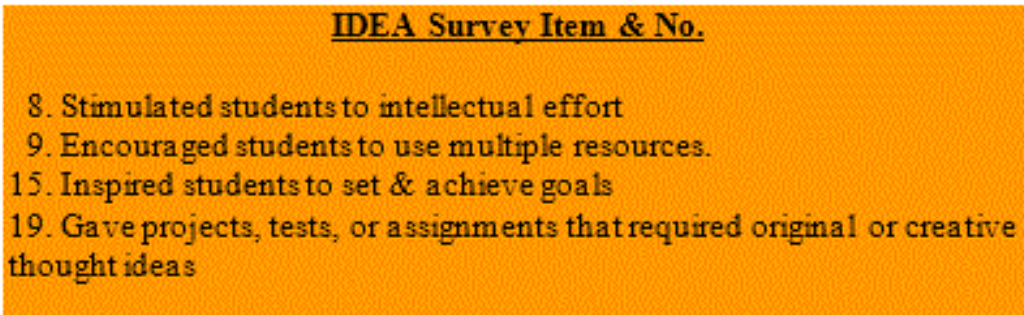

IDEA Survey item \& No.

1. Displayed a personal interest in students and their learning 2. Found ways to help students answer their own questions 4. Demonstrated importance \& significance of subject matter

5. Formed teams or discussion groups

7. Explained the reason for students' academic performance

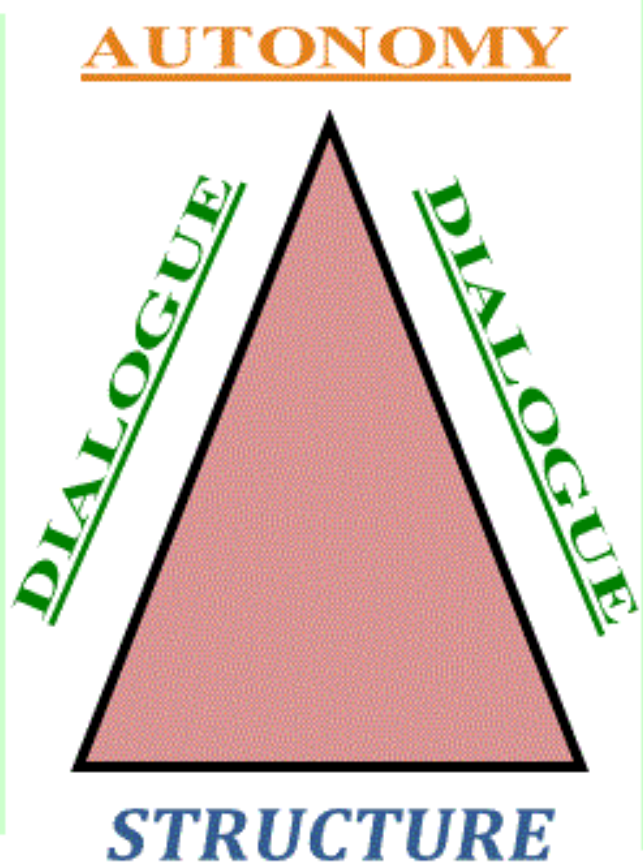
IDEA Survey Item \& No.

13. Introduced stimulating ideas about the subject 16. Asked students to share ideas \& experiences with others whose backgrounds \& viewpoints differ from their own 17. Provide timely \& frequent feedback 18. Asked students to help each other understand ideas or concepts 20. Encouraged student/faculty

\section{IDEA Survey Item \& No.}

3. Scheduled course work to encourage students to stay up to date in their work

6. Made it clear how each topic fit into the course

10. Explained course material concisely

11. Related course materialto real life situations

12. Gave tests, projects etc. that covered the most important points of the course

14. Involved students in hands-on projects

IDEA TEACHING METHODS \& STYLES

Figure: 2

The Conceptual Framework 


\section{METHODOLOGY AND DATA COLLECTION}

An independent samples t-tests was used for the purpose of examining whether a statistically significant difference exists between the TM\&S of DE and F2F student ratings at an Open University in the Mid-Atlantic region of the U.S. with respect to student surveys through the lens of Moore's TDT (see Figure 2) (IDEA, 2013; Moore, 2012). Twenty null hypotheses were stated to correlate with the 20 TM\&S questions listed on the student survey for a range of classes beginning with SOC 101 Introduction to Sociology and ending with SOC 340 Applied Research in the Behavioral Sciences offered from September 6, 2011 through December 19, 2013. Student ratings for 765 classes (488 F2F and 277) were evaluated.

The sampling approach was a comprehensive one that included an analysis of all of the completed surveys for the stated courses and dates. This was an Ex Post Facto design (Campbell \& Stanley, 1963) as the data was collected prior to this study. The data for each class was separated into DE and F2F categories.

\section{The Instrument}

The data for this study was drawn from a commercially available survey instrument that has been used at the study site for twenty-five years. It is a student-centered survey that is designed to obtain the student's evaluation of both the course he or she has just completed and the instructor responsible for teaching the course (IDEA, 2013). Student evaluations of instructor performance, including this particular instrument, have been shown to be both valid and reliable (Benton \& Cashin, 2012; Renaud \& Murray, 2005; Theall \& Franklin, 2001). There are no identifying factors to any student contained on the instrument. Therefore, all student information was kept confidential and anonymous.

\section{Content Validity}

Descriptions of the TDT constructs of autonomy, dialogue and structure and the categorization of the TM\&S variables considered consistent with the TDT constructs were sent to a TDT expert, the Senior Survey Research Officer and the Chair of the Behavior Science Department at the study site for their comments for the purpose of testing content validity. The TDT expert did not respond. The senior researcher and the Chair both responded in the affirmative.

\section{Significance and Effect Size}

The independent samples t-test was run using IBM SPSS v. 21. P values at the .05 level of significance and effect size magnitudes for each of the $\mathbf{2 0}$ survey variables are reported. The effect size magnitude calculations were based on a Cohen's $d$ statistic of low, medium and high effect size (Field, 2013; Hinkle et al, 2003). 


\section{RESULTS}

The mean scores for 15 courses offered in 765 classes (277 DE \& 488 F2F) of IDEA surveys were analyzed from Fall 2011 to Fall 2013 inclusive. Of the 277 DE classes evaluated, there were 2216 responses for an average of 8 responses per class. Of the 488 F2F classes evaluated, there were 4880 responses for an average of 10 responses per class. A total of 7184 responses were examined in the study. Of the 20 null hypotheses from the IDEA TM\&S surveys, 16 had statistically significant results.

The analyses of the results for hypotheses categorized under the TDT construct autonomy (Table 5) indicate that three of the four $\left(H \emptyset_{8}, H \emptyset_{15} \& H \emptyset_{19}\right)$ yielded statistically significant results. Those three hypotheses were rejected. All three hypotheses returned Cohen's $d$ magnitudes of less than $\mathbf{3 0}$ indicating small effects. Taking this information into account, there is likelihood that the effect of the particular variable is not substantive. $\mathrm{H} \varnothing_{9}$ with a pvalue greater than .05 was accepted.

Table: 5

Independent Samples t-Test Results for TDT Construct Autonomy

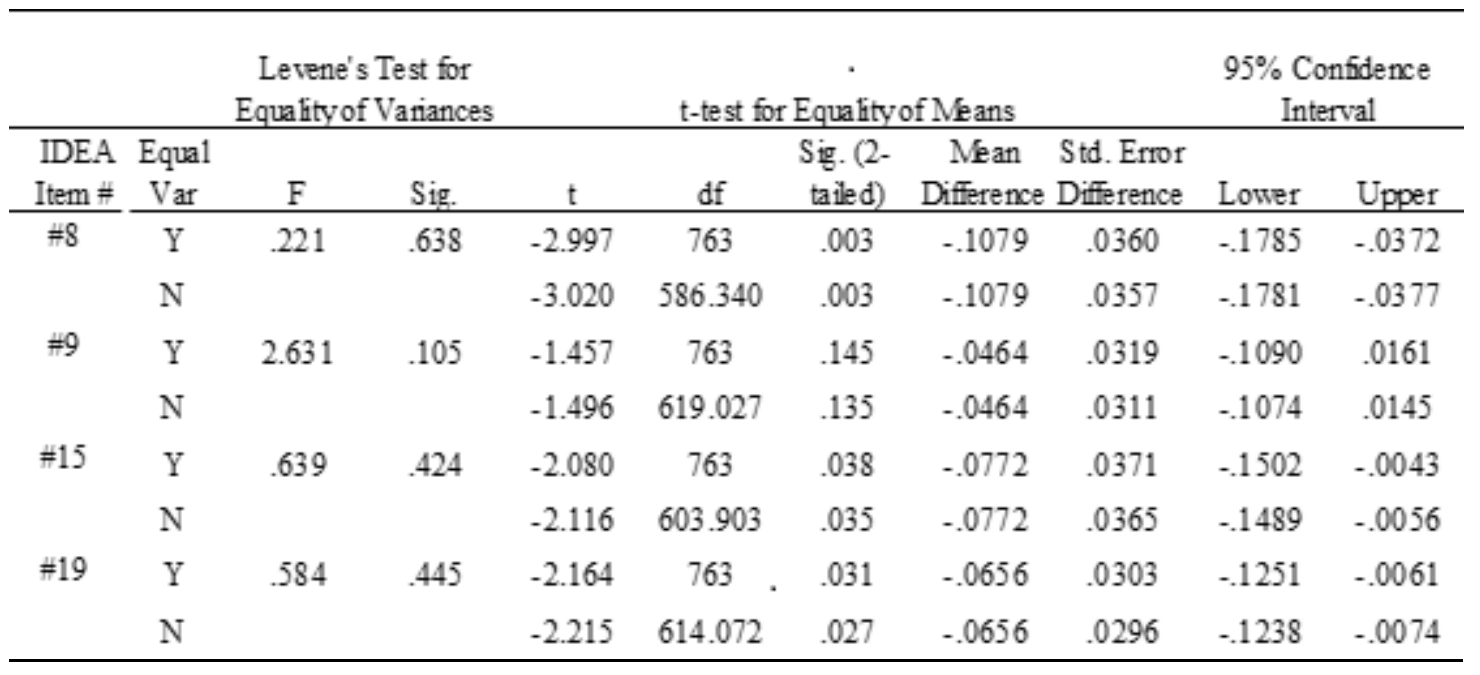

The analyses of the results for hypotheses categorized under the TDT construct dialogue (Table 6) indicate that eight of the ten $\left(H \emptyset_{1}, H \emptyset_{2}, H \emptyset_{4}, H \emptyset_{5}, H \emptyset_{13}, H \emptyset_{17}, H \emptyset_{18} \& H \emptyset_{20}\right)$ yielded statistically significant results. Those eight hypotheses were rejected. Three of the eight statistically significant hypotheses retuned medium effect sizes $\left(H \emptyset_{1} / d=.55, H \emptyset_{2} / d=.52\right.$, \& $\left.\mathrm{H} \emptyset_{4} / d=.45\right)$ indicating a more substantive effect. The remaining five hypotheses returned small effect sizes. 
Table: 6

Independent Samples t-test for the TDT Construct Dialogue.

\begin{tabular}{|c|c|c|c|c|c|c|c|c|c|c|}
\hline \multirow[b]{2}{*}{$\begin{array}{c}\text { IDEA } \\
\text { ITEM = }\end{array}$} & \multirow[b]{2}{*}{$\begin{array}{c}\text { EQUAL } \\
\text { VAR } \\
\text { ASSUM }\end{array}$} & \multicolumn{3}{|c|}{$\begin{array}{c}\text { Levene's Test for } \\
\text { Equality of Variances }\end{array}$} & \multicolumn{4}{|c|}{ t-test for Equality of Means } & \multicolumn{2}{|c|}{$\begin{array}{l}95 \% \text { Confidence } \\
\text { Interval of the } \\
\text { Difference }\end{array}$} \\
\hline & & $\mathrm{F}$ & Sig. & $\mathrm{t}$ & df & $\begin{array}{l}\text { Sig. (2- } \\
\text { tailed) }\end{array}$ & $\begin{array}{c}\text { Mean } \\
\text { Diff }\end{array}$ & $\begin{array}{l}\text { Std. Error } \\
\text { Dif }\end{array}$ & Lower & Upper \\
\hline \multirow[t]{2}{*}{$=1$} & $\mathrm{Y}$ & 8.705 & & -7.471 & 763 & .000 & -.2431 & .0325 & -.3070 & -.1792 \\
\hline & $\mathrm{N}$ & & .003 & -7.135 & 498.684 & .000 & -.2431 & .0341 & -.3100 & -.1762 \\
\hline \multirow[t]{2}{*}{$=2$} & $\mathrm{Y}$ & 2.584 & .108 & -6.932 & 763 & .000 & -.2520 & .0364 & -.3234 & -.1807 \\
\hline & $\mathrm{N}$ & & & -6.844 & 551.642 & .000 & -.2520 & .0368 & -.3244 & -.1797 \\
\hline \multirow[t]{2}{*}{$=4$} & $\mathrm{Y}$ & 6.949 & & -6.091 & 763 & .000 & -.1829 & .0300 & -.2419 & -.1240 \\
\hline & $\mathrm{N}$ & & .009 & -5.836 & 503.841 & .000 & -.1829 & .0313 & -.2445 & -.1213 \\
\hline \multirow[t]{2}{*}{$=5$} & $\mathrm{Y}$ & 4.907 & & -2.218 & 763 & .027 & -.0937 & .0422 & -.1766 & -.0108 \\
\hline & $\mathrm{N}$ & & .027 & -2.316 & 649.416 & .021 & -.0937 & .0405 & -.1732 & -.0143 \\
\hline \multirow[t]{2}{*}{$=7$} & $\mathrm{Y}$ & 1.318 & .251 & -1.068 & 763 & .286 & -.0407 & .0382 & -.1156 & .0342 \\
\hline & $\mathrm{N}$ & & & -1.041 & 531.513 & .298 & -.0407 & .0391 & -.1176 & .0361 \\
\hline \multirow[t]{2}{*}{$=13$} & $\mathrm{Y}$ & .126 & .722 & -3.804 & 763 & .000 & -.1333 & .0351 & -.2022 & -.0645 \\
\hline & $\mathrm{N}$ & & & -3.791 & 567.748 & .000 & -.1333 & .0352 & -.2024 & -.0643 \\
\hline \multirow[t]{2}{*}{$=16$} & $Y$ & 2.795 & .095 & -1.499 & 763 & .134 & -.0500 & .0334 & -.1156 & .0155 \\
\hline & $\mathrm{N}$ & & & -1.541 & 622.117 & .124 & -.0500 & .0325 & -.1138 & .0137 \\
\hline \multirow[t]{2}{*}{$=17$} & $\mathrm{Y}$ & .232 & .630 & -2.638 & 763 & .009 & -.1126 & .0427 & -.1963 & -.0288 \\
\hline & $\mathrm{N}$ & & & -2.657 & 586.113 & .008 & -.1126 & .0424 & -.1957 & -.0294 \\
\hline \multirow[t]{2}{*}{$=18$} & $\mathrm{Y}$ & 1.618 & .204 & -2.196 & 763 & .028 & -.0813 & .0370 & -.1540 & -.0086 \\
\hline & $\mathrm{N}$ & & & -2.245 & 612.499 & .025 & -.0813 & .0362 & -.1525 & -.0102 \\
\hline \multirow[t]{2}{*}{$=20$} & $\mathrm{Y}$ & .375 & .540 & -3.729 & 763 & .000 & -.1453 & .0390 & -.2218 & -.0688 \\
\hline & $\mathrm{N}$ & & & -3.715 & 566.890 & .000 & -.1453 & .0391 & -.2222 & -.0685 \\
\hline
\end{tabular}

The analyses of the results for hypotheses categorized under the TDT construct structure (Table 7) indicate that five of the six $\left(H \emptyset_{3}, H \emptyset_{6}, H \emptyset_{10}, H \emptyset_{11} \& H \emptyset_{14}\right)$ yielded statistically significant results. Those five hypotheses were rejected. Two of the five statistically significant hypotheses returned medium effect sizes $\left(H \emptyset_{6} / d=.38 \& H \emptyset_{10} / d=.46\right)$ indicating a more substantive effect. 
Table: 7

Independent Samples t-Test for the Construct Structure

\begin{tabular}{|c|c|c|c|c|c|c|c|c|c|c|}
\hline \multirow[b]{2}{*}{$\begin{array}{l}\text { IDEA } \\
\text { It em } \\
\quad \#\end{array}$} & \multicolumn{4}{|c|}{$\begin{array}{l}\text { Levene's Test } \\
\text { for Equality } \\
\text { of Variances }\end{array}$} & \multicolumn{4}{|c|}{ t-test for Equality of Means } & \multicolumn{2}{|c|}{$\begin{array}{c}95 \% \text { Confidence } \\
\text { Interval of the } \\
\text { Difference }\end{array}$} \\
\hline & $\begin{array}{l}\text { EQUAL } \\
\text { of VAR } \\
\text { ASSUM }\end{array}$ & $\mathrm{F}$ & Sig & $\mathrm{t}$ & df & $\begin{array}{l}\text { Sig. (2- } \\
\text { tailed) }\end{array}$ & $\begin{array}{c}\text { Mean } \\
\text { Diff }\end{array}$ & $\begin{array}{c}\text { Std. } \\
\text { Error } \\
\text { Diff } \\
\end{array}$ & Lower & Upper \\
\hline \multirow[t]{2}{*}{$\# 3$} & $\mathrm{Y}$ & .096 & .757 & -2.458 & 763 & .014 & -.0792 & .0322 & -.1425 & -.0160 \\
\hline & $\mathrm{N}$ & & & -2.531 & 624.815 & .012 & -.0792 & .0313 & -.1407 & -.0178 \\
\hline \multirow[t]{2}{*}{$\# 6$} & $\mathrm{Y}$ & .214 & .643 & -5.057 & 763 & .000 & -.1642 & .0325 & -.2280 & -.1005 \\
\hline & $\mathrm{N}$ & & & -5.029 & 564.137 & .000 & -.1642 & .0327 & -.2284 & -.1001 \\
\hline \multirow[t]{2}{*}{$\# 10$} & $\mathrm{Y}$ & .041 & .840 & -4.288 & 763 & .000 & -.1651 & .0385 & -.2407 & -.0895 \\
\hline & $\mathrm{N}$ & & & -4.330 & 590.383 & .000 & -.1651 & .0381 & -.2401 & -.0902 \\
\hline \multirow[t]{2}{*}{$\# 11$} & $\mathrm{Y}$ & 1.437 & .231 & -6.581 & 763 & .000 & -.2078 & .0316 & -.2698 & -.1458 \\
\hline & $\mathrm{N}$ & & & -6.476 & 546.482 & .000 & -.2078 & .0321 & -.2709 & -.1448 \\
\hline \multirow[t]{2}{*}{$\# 12$} & $\mathrm{Y}$ & 3.236 & .072 & -1.541 & 763 & .124 & -.0460 & .0299 & -.1047 & .0126 \\
\hline & $\mathrm{N}$ & & & -1.586 & 623.940 & .113 & -.0460 & .0290 & -.1031 & .0110 \\
\hline \multirow[t]{2}{*}{$\# 14$} & $\mathrm{Y}$ & .022 & .883 & -3.096 & 763 & .002 & -.1113 & .0360 & -.1819 & -.0407 \\
\hline & $\mathrm{N}$ & & & -3.079 & 564.220 & .002 & -.1113 & .0361 & -.1823 & -.0403 \\
\hline
\end{tabular}

\section{DISCUSSION AND CONCLUSION}

While the constructs of dialogue and structure were found to be important in reducing TD in computer mediated DE classes, the construct autonomy returning 3 of 4 statistically significant results with only small effect sizes was found not to paly an important role in reducing TD. As with the mean scores of DE and F2F classes for dialogue, those for structure are similar and skewed to the high end of 5.0, which causes one to consider the differences between student evaluations of F2F and DE classes at the research site to be more of a preference for F2F classes than dissatisfaction with DE classes.

Moore (2010, p. 19) maintained, "as dialogue increases, transactional distance decreases [and] as structure increases, transactional distance increases." We believe the results of this study indicate the opposite. That is, as structure that highlights the importance of student/instructor engagement (dialogue/interaction) increases, TD decreases. With respect to the relationship between structure and dialogue/interaction, one Ph. D. student (Jacki, 2010) blogged that student/instructor engagement (i.e., dialogue/interaction) is necessary for an online course. She references Salmon's Five Stage Model for online classes. Salmon's Stage 1 holds for instructors encouraging students to interact in the class. Stage 4 of 5 encourages students to lead the class and keep the interaction ongoing (See Salmon \& Shepard, 2004).

\section{PROPOSED MODEL}

The focus of the current study has been limited to the Open University in the Mid-Atlantic region and as such is much narrower in scope than what Professor Moore intends. Nevertheless, the results of the current study have encouraged this researcher to pursue even further study of TDT 
as it applies to such situations. Based on the reviewed literature as well as the results of the current study, a proposal for a computer mediated distance education model (CMDEM) is presented in Figure 3 As has been discussed in this paper and has been found by others (Benson \& Samarawickrema, 2009; Kanuka, Collett, \& Caswell, 2002; Murphy \& Cifuentes, 2001; Wikeley \& Muschamp, 2004), the results of the current study highlight the magnitude of the TM\&S variables categorized in the TDT constructs of dialogue and structure. The CMDEM assumes instructor engagement and relies exclusively on DE courses delivered by way of the Internet using such systems as Blackboard, Web CT, Angel, Moodle among others existing now or in the future.

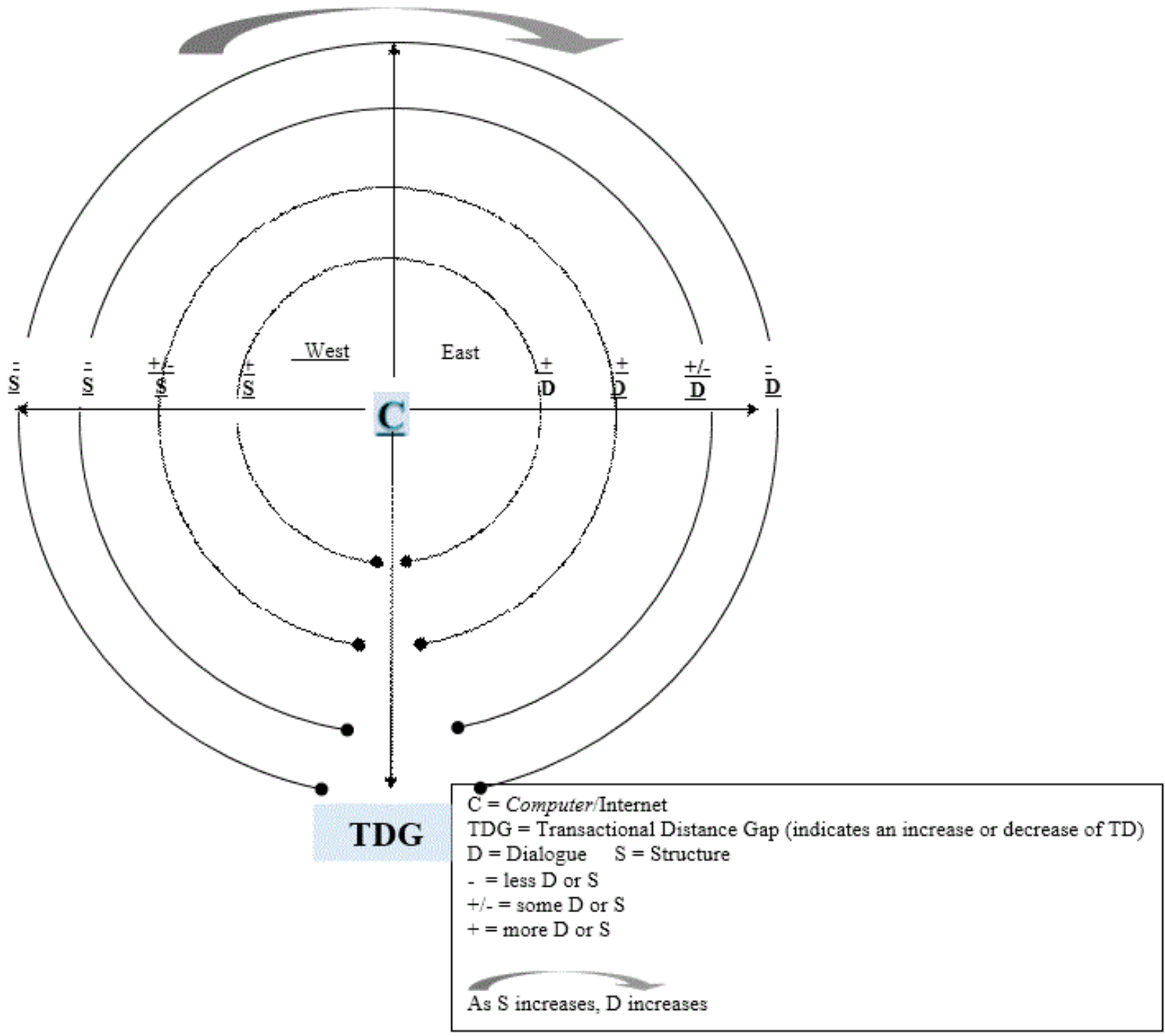

Figure: 3

Computer Mediated DE Model (CMDEM) 
The model includes four (4) concentric rings around the constant (C) which represents the computer with access to the Internet. There is a vertical axis that divides each ring into an east/west orientation. The portion of the rings on the west axis represents "structure" (S); the portion on the east axis represents "dialogue" (D). Each ring is identified by a (-) indicating lesser or a $(+)$ indicating greater or a $(+/)$ indicating some. As an example, both the outermost western rings (representing structure) and outermost eastern rings (representing dialogue) are identified with a (-) indicating less structure/dialogue. Thus, the outermost ring indicates the largest transactional distance gap (TDG), which indicates greater TD. The innermost rings, which are comprised of an eastern half identified as ( + ) and a western half also identified as $(+)$, represents the smallest TDG indicating less TD. Thus, the CMDEM model theorizes that when DE classes are structured in a way that focuses on the need for dialogue and interaction, TD will decrease. Therefore, as structure increases, so does dialogue/interaction.

\section{BIODATA and CONTACT ADDRESSES of the AUTHORS}

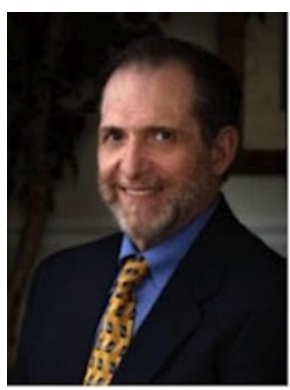

Dr. Glenn J. FORTE was formerly the Vice President for Operations for a pharmaceutical packaging firm in the USA. He retired early from that position in 2005 and has turned his attention to higher education. He earned his doctorate from The Executive Leadership Doctoral Program, The Graduate School of Education \& Human Development at The George Washington University, Washington, DC. He holds a Masters of Arts degree in Theology and Religious Studies from Villanova University in Villanova, PA. USA and a Bachelors of Arts degree in Liberal Arts from Kutztown State College in Kutztown, PA, USA

Dr. Glenn J. FORTE

Behavioral Science Department

The College of Social \& Behavioral Science

Wilmington University, 320 N. DuPont HWY

New Castle, DE, USA. 19720

Phone: +11 4848808862

Email: glenn.j.forte@wilmu.edu

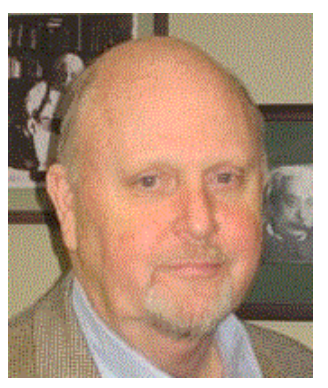

Prior to his career in higher education Dr. David R. SCHWANDT was the Human Resource Director of the United States of American's General Accounting Office (GAO) in Washington, DC, USA. He is the founder and former director of The Executive Leadership Doctoral Program of The Graduate School of Education \& Human Development at The George Washington University. He holds a Ph.D. in Organizational Administration from Wayne State University in Detroit, MI, USA, a Master of Science in Physics from Western Michigan University and a Bachelor of Science in Physics from Eastern Michigan University.

Professor Emeritus, Dr. David R. SCHWANDT

The Graduate School of Education \& Human Development

The George Washington University

Enterprise Hall

44983 Knoll Square,

Ashburn, VA 20147: USA.

Phone: 7039784059

Email: schwandt@gwu.edu 


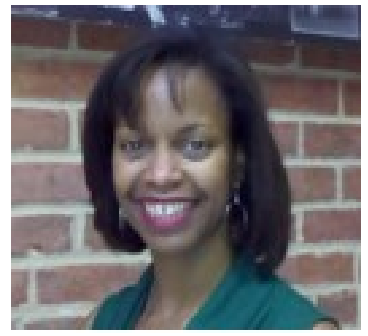

Dr. Susan SWAYZE holds a Ph.D. in Education from the University of California, Los Angeles, CA, USA, an MBA from Duke University, Durham, NC, USA and a Master of Arts in Education from the University of California, Los Angeles, CA, USA. She was a Research Fellow at the Southwest Center for Educational Equity, a Research Scholar in the Afro-American Studies Program for Interdisciplinary Research at the University of California, Los Angeles, LA, USA and an Educational Policy Fellow at the Instituted for Educational Leadership.

\author{
Dr. Susan SWAYZE \\ Educational Research Department \\ Graduate School of Education \& Human Development \\ The George Washington University, Washington, DC, USA. \\ PO Box 1092, Stirling, VA 20167 \\ Phone: 5715533773 \\ Email: swayze@gwu.edu
}

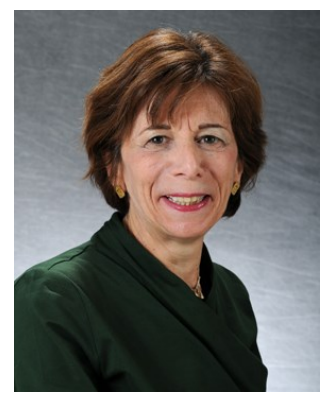

Dr. Joan BUTLER served as an executive within the pharmaceutical industry, and has held various positions of increasing responsibility in her 30-year tenure. Dr. Butler's passion in industry was being a project manager (PM) leading interdisciplinary teams to develop new technologies to meet patients' unmet medical needs. She was chosen as the industry PM representative loaned to the US Food \& Drug Administration to aid the implementation of the team based managed review process' within the Centers for Drugs and Biologics for PDUFA implementation.

\title{
Dr. Joan BUTLER
}

Clinical Research Department

The George Washington University

Washington, DC, USA

Phone: 2029944837

Email: jbutler@gwu.edu

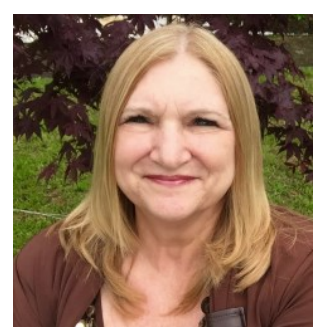

Dr. Merrill ASHCRAFT earned a doctorate earned her doctorate from The Executive Leadership Doctoral Program, The Graduate School of Education \& Human Development at The George Washington University, Washington, DC. She retired as a Resource Manager from the US Civil Services, Transportation \& Environmental Services where she managed annual budgets in excess of $\$ \mathbf{1 0 0 , 0 0 0 , 0 0 0}$. Throughout her career she was considered an agent of change who created innovations that saved millions of dollars. In addition to many other awards and honors, she was named to the US Navy's Public Works Center Hall of Fame for significant cost savings and she was the 2005 Executive Leadership Doctoral Program Cohort 15 recipient of the George Washington University's Executive Leadership Ralph Stone Award for excellence in doctoral studies.

Dr. Merrill ASHCRAFT

Strategic Statistics Consulting

Chesapeake, VA, USA

Phone: 7574655230

Email: jmashcraft@verizon.net 


\section{REFERENCES}

Allen, I. E. \& Seaman, J. (2014). Grade change: Tracking online education in the United States, Babson Park, MA: Babson Survey Research Group.

Benton, S. L., \& Cashin, W. E. (2012). Student ratings of teaching: A summary review and literature [Electronic Version], \#50. Retrieved from www.theideacenter.org.

Bernard, R. M., Abrami; P. C., Lou, Y., Borokhovski, E., Wade, A., Wozney, L., Wallet, P. A., Fiset, M. \& Huang, B. (2004). How does distance education compare with classroom instruction? A meta-analysis of the empirical literature. Review of Educational Research, 74(3), 379-439.

Benson, R., \& Samarawickrema, G. (2009). Addressing the context of learning: Using transactional distance theory to inform design. Distance Education, 30(1), 5-21.

Campbell. D. T., \& Stanley, J. C. (1963). Experimental and quasi-experimental designs for research. Boston, MA: Houghton Mifflin Company.

Connolly, M., Jones, C., \& Jones, N. (2007). New approaches, new visions: Capturing teacher experiences in a brave new online world. Open Learning, 22(1), 43-56.

Dewey, J. \& Bentley, A. F. (1949). Knowing and the known. Boston: Beacon Press.

Dron, J., Seidel, C., \& Litten, G. (2004). Transactional distance in a blended learning environment. ALT-J, Research in Learning Technology, 12(2), 163-174.

Field, A. (2013). Discovering statistics using IBM SPSS statistics: And sex drugs and rock 'n' roll ( $4^{\text {th }}$ ed. $)$. Los Angeles, CA: Sage.

Fulford, C. P., \& Zhang, S. (1993). Perceptions of interaction: The critical predictor in Distance Education. The American Journal of Distance Education, $7(3), 8-21$.

Gorsky, P., \& Caspi, A. (2005a). A critical analysis of transactional Distance theory. The Quarterly Review of Distance Education, 6(1), 1-11.

Gorsky, P., \& Caspi, A. (2005b). Dialogue: A theoretical framework for distance education instructional systems. British Journal of Educational Technology, 36(2), 137-144.

Gorsky, P., Caspi, A., \& Trumper, R. (2004). Dialogue in a distance education physics course. Open Learning, 19(3), 265-277.

Hinkle, D. E., Wiersma, W., \& Jurs, S. G. (2003). Applied statistics for the behavioral sciences ( $5^{\text {th }}$ ed.). Boston, MA: Houghton Mifflin Company.

Holmberg, B. (2003). A theory of distance education based on empathy. In M. G. Moore \& W. G. Anderson (Eds.), Handbook of distance education (2nd. ed., pp. 79-86). Mahwah, NJ: Lawrence Erlbaum Associates, Publisher.

IDEA. (2013). Feedback services for higher education since 1975. IDEA Center: Insight Improvement Impact. Retrieved from www.theideacenter.org/services

Jacki. (2010). E-reflections: Salmon's five stage model. Retrieved from www.gillysalmon.com/ five-stage-model.html

Kanuka, H., Collett, D., \& Caswell, C. (2002). University instructor perceptions of the use of asynchronous text-based discussion in distance courses. The American Journal of Distance Education, 16(3), 151-167.

Lear, J. L., Isernhagen, J. C., LaCost, B., \& King, J. W. (2009). Instructor presence for WebBased classes. Delta Pi Epsilon, LI(2), 86-99. 
Moore, M. G. (1997). Theory of transactional distance. In D. Keegan (Ed.), Theoretical Principles of Distance Education (pp. 22-38). London: Routledge.

Moore, M. G. (2010). The theory of transactional distance. In The Handbook of Distance Education (pp. 1-21). University Park, PA: The Pennsylvania State University.

Moore, M. G. (2012). The theory of transactional distance (pp. 1-25). University Park, PA.

Murphy, K. L., \& Cifuentes, L. (2001). Using Web tools, collaborating, and learning online. Distance Education, 22(2), 285-305.

Renaud, R. D., \& Murray, H. G. (2005). Factorial validity of student ratings of instruction. Research in Higher Education, 46(8), 929-953.

Salmon, G., \& Shephard, D. (2004). All things in moderation. Retrieved October 30, 2012, from http: //www.atimod.com/profile/atimod.shtml

Theall, M., \& Franklin, J. (2001). Looking for bias in all the wrong places: A search for truth or a witch hunt in student ratings of instruction. New Directions for Institutional Research, 109(Spring), 45-56.

Tsui, A. B. M., \& Ki, W. W. (1996). An analysis of conference interactions on TeleNex: A computer network for ESL teachers. Educational Technology Research and Development, 44(4), 23-44.

Wikeley, F., \& Muschamp, Y. (2004). Pedagogical implications of working with doctoral students at a distance. Distance Education, 25(1). 